\title{
Profilaxia antirrábica no município de Uberlândia, Minas Gerais
}

\section{Antirabies prophylaxis in the city of Uberlândia, Minas Gerais}

\author{
Adriano Soares Marques ${ }^{1}$. Ailton Gonçalves da Silva Filho ${ }^{1}$. Dayane Martins do Carmo ${ }^{1}$. Marcelo Pellizzaro \\ Dias Afonso ${ }^{1}$. Stefan Vilges de Oliveira ${ }^{1}$. \\ 1 Universidade Federal de Uberlândia (UFU), Uberlândia, Minas Gerais, Brasil.
}

\section{RESUMO}

Objetivo: Caracterizar a profilaxia antirrábica no município de Uberlândia, Minas Gerais. Metodologia: baseou-se na utilização do tabulador de dados Tabwin 3.2 para avaliação das fichas de notificação do Sistema de Informação de Agravos de Notificações (SINAN), no período de 2008 a 2017. Resultados: No recorte temporal escolhido foram notificadas 23.090 profilaxias antirrábicas no município em 2018. Os mais acometidos foram homens 50,79\%, e os principais responsáveis pelas agressões foram os cães $81,38 \%$, gatos $11,16 \%$ e morcegos $0,71 \%$. A observação de evolução clínica do animal é a principal conduta adotada $22,38 \%$, e a maioria evolui de forma sadia $80,96 \%$. Conclusão: $O$ trabalho contribui para o acompanhamento do perfil epidemiológico da profilaxia antirrábica na cidade. Permite-se assim, diagnosticar condições de maior vulnerabilidade e a apresentação epidemiológica deste agravo a saúde, o que possibilita a melhoria desses atendimentos minimizando o risco da transmissão.

Palavras-chave: Vigilância em Saúde Pública. Aplicações da epidemiologia. Vacinas antirrábicas. Raiva.

\section{ABSTRACT}

Objective: To characterize anti-rabies prophylaxis in the city of Uberlândia, Minas Gerais. Methodology: Was based on the use of the Tabwin 3.2 data tabulator for the evaluation of the notification records of the Notifiable Diseases Information System, from 2008 to 2017. Results: In the chosen temporal cut 23,090 anti-rabies prophylaxis was reported in the city in 2018. The most affected were men $50.79 \%$, and the main ones responsible for the aggressions were dogs $81.38 \%$, cats $11.16 \%$ and bats $0.71 \%$. The observation of clinical evolution of the animal is the main behavior adopted $22.38 \%$ and most of them live $80.96 \%$. Conclusion: The work contributes to the monitoring of the epidemiological profile of anti-rabies prophylaxis in the city. It is thus possible to diagnose conditions of greater vulnerability and the epidemiological presentation of this health impairment, which makes it possible to improve these services minimizing the risk of transmission.

Keywords: Public Health Surveillance. Uses of epidemiology. Rabies vaccines. Rabies.

Autor correspondente: Stefan Vilges de Oliveira, Universidade Federal de Uberlândia, Faculdade de Medicina, Departamento de Saúde Coletiva, Avenida Pará, 1720, Umuarama, Uberlândia, Minas Gerais, Brasil. CEP: 38405-320. Telefone: +55 34 3225-8273. E-mail: stefan@ufu.br

Conflito de interesses: Não há qualquer conflito de interesses por parte de qualquer um dos autores.

Recebido em: 22 Jan 2019; Revisado em: 09 Jul 2019; Aceito em: 30 Set 2019. 


\section{INTRODUÇÃO}

Afecções relacionadas à animais são de grande importância epidemiológica; dentre elas, a raiva apresenta-se com uma zoonose viral que atinge o Sistema Nervoso Central (SNC) dos mamíferos, incluindo o ser humano, e resulta em uma mortalidade aproximada a $100 \%$ dos casos. O agente responsável pelo distúrbio é um vírus de RNA da família Rhabdoviridae e gênero Lyssavirus. A transmissão se baseia na mordedura, lambedura ou arranhão de animais infectados e inoculação do vírus por meio de secreções contaminadas. Ainda, sua circulação no ambiente se dá por 4 ciclos básicos: urbano, rural, silvestre e silvestre aéreo. ${ }^{1}$

Segundo estimativa da Organização Mundial da Saúde (OMS), aproximadamente 60.000 pessoas morrem em decorrência da raiva, anualmente. ${ }^{2} \mathrm{O}$ cenário de casos identificados da doença nas Américas é caracterizado por uma ascensão de ataques mediados por morcegos em detrimento aos cães e gatos, deve-se isso ao incentivo a campanhas de vacinação aos animais domésticos. ${ }^{3}$

No Brasil, registrou-se 25 casos de raiva humana no período de 2010 a 2017, redução notória quando se compara a um mesmo recorte temporal de 8 anos - período de 2002 a 2009 - em que foram catalogados 116 casos da doença no país. ${ }^{4,5}$ No estado de Minas Gerais, o último caso de raiva humana contabilizado se deu em 2012 em Rio Casca, na Zona da Mata, onde um produtor rural foi atacado por um morcego. ${ }^{6}$

No município de Uberlândia, a presença de animais positivos, tanto em ambiente rural/silvestre, quanto em área urbana é recorrente. Foram contabilizados 23 casos de morcegos positivos para a doença no período de 2001 a 2018. Destes, aproximadamente, $40 \%$ encontrados na região central da cidade em bairros como Centro, Planalto, Martins e Vigilato Pereira (Dados não publicados, cedidos pela Unidade de Vigilância de Zoonoses da Secretaria Municipal de Saúde do município de Uberlândia).

É importante salientar que o protocolo padrão de atendimento, na suspeita de infecção por raiva, leva em consideração a possibilidade de observação da evolução clínica do animal responsável pelo ataque, se o animal evoluir bem em até 10 dias, o caso é encerrado. De outro modo, indica-se a imediata imunização, em acidente por animal silvestre ou silvestre aéreo, em que não é possível a observação controlada destas espécies e ainda, de características do ferimento como proximidade com o Sistema Nervoso Central, profundidade, locais muito inervados, tamanho e quantidade. ${ }^{7,8}$

Deste modo, a adoção de protocolos de atendimento pré e pós-exposição ao patógeno, objetiva o melhor uso do recurso disponível ao atendimento profilático, ao se buscar a efetividade de ação contra o efeito deletério da doença e ainda, em associação, evitar o uso desnecessário desses mecanismos. ${ }^{4}$

Este estudo visa descrever o perfil epidemiológico das profilaxias antirrábicas na cidade de Uberlândia-MG, avaliando as condutas exercidas nos casos de ataque, bem como os seus desfechos.

\section{MATERIAIS E MÉTODOS}

O trabalho desenvolvido é caracterizado por um estudo transversal, descritivo de caráter quantitativo, em que foram extraídas informações epidemiológicas da base de dados do Sistema de Informação de Agravos de Notificações (SINAN) do Ministério da Saúde (MS) do Brasil.

A cidade de Uberlândia é um município referencial da região do Triângulo Mineiro, com população estimada em 683.247 pessoas em 2018 e uma área total da unidade regional estimada em 4.115.206 Km². Uberlândia se insere no cerrado brasileiro e está a $534 \mathrm{Km}$ a oeste da capital Belo Horizonte. O clima da região é composto por duas fases bem definidas: seca entre os meses de abril a setembro e chuvosa de outubro a março. $\mathrm{O}$ Produto Interno Bruto (PIB) per capita do município foi de R\$ 44.612,40 em 2015 e o Índice de Desenvolvimento Humano Municipal (IDHM) de 0.789 em 2017.9,10

O período da análise foi de 1 de janeiro de 2008 a 31 de dezembro de 2017. A base de dados foi disponibilizada pelo MS segundo protocolo do Serviço de Informação ao Cidadão número 25820006595201811.

Para tanto, considerou os casos notificados de profilaxia antirrábica na base de dados consultada e incluiu todos os acidentes que envolveram qualquer contato que oferecesse risco potencial de contaminação pelo Lyssavírus.

O principal instrumento de observação foi a ficha de notificação e investigação epidemiológica disponibilizada pelo SINAN para profilaxia antirrábica humana http://www.portalsinan. saude.gov.br/images/documentos/Agravos/Atendimento $\% 20$ Anti-rabico/anti_rabico_v5.pdf.

Foram selecionados 13 campos para análise dos profilaxias antirrábicas, são eles: [10] Idade, [11] Sexo, [14] Escolaridade, [32] Tipo de exposição ao vírus rábico, [40] Espécie do animal agressor, [41] Condição do animal para fins de conduta do tratamento, [42] Animal passível de observação, [43] Tratamento indicado, [48] Condição final do animal, [49] Interrupção do tratamento, [50] Qual motivo da interrupção, [51] Houve abandono do tratamento, a Unidade de Saúde procurou o paciente, e o campo [53] Indicação de soro antirrábico.

Os dados foram analisados pelos softwares Tabwin 3.2 e tabulados em planilhas de dados Microsoft Office Excel ${ }^{\circledR}$, posteriormente, passaram por uma análise estatística descritiva utilizando-se medidas de frequência, tendência central e de dispersão. Os coeficientes de incidência dos acidentes por animais com potencial de transmissão para raiva foram calculados para o município e por ano do estudo (calculados por 100 mil habitantes) apresentados com base nos casos notificados. Para análise da incidência foram utilizados dados das estimativas populacionais obtidos a partir dos censos demográficos (2000 e 2010) e das Pesquisas Nacionais de Amostra em Domicílio (PNAD). ${ }^{8}$ Para os cálculos dos 
coeficientes médios de incidência, utilizou-se a média aritmética dos respectivos coeficientes anuais. Neste trabalho foram consultados dados não nominais, agregados e de acesso público. Por estes aspectos, não foi necessário a apreciação do comitê de ética em pesquisa.

\section{RESULTADOS}

No período foram notificadas 23.090 profilaxias antirrábicas no município de Uberlândia, o maior número de notificações foi no ano de 2017 (Gráfico 1). A incidência média de casos foi 358,99 a cada 100 mil habitantes (variando de 254,27 a 437,76) no período. A avaliação dos casos de agressão estratificados por sexo mostrou que homens (50,79\%) são mais acometidos que mulheres (49\%).

Pode-se notar relativa variação na quantidade de doses aplicadas. O ano de menor número é de 2010 com 391 doses utilizadas. Há um grande salto na quantidade no ano seguinte com 1050 doses, perdendo apenas para o último ano de avaliação em 2017, com 1153 doses aplicadas (Gráfico 1).

Gráfico 1. Profilaxia antirrábica, doses aplicadas e incidência de profilaxia antirrábica por ano de notificação. Uberlândia, Minas Gerais, Brasil, 2008 a 2017.

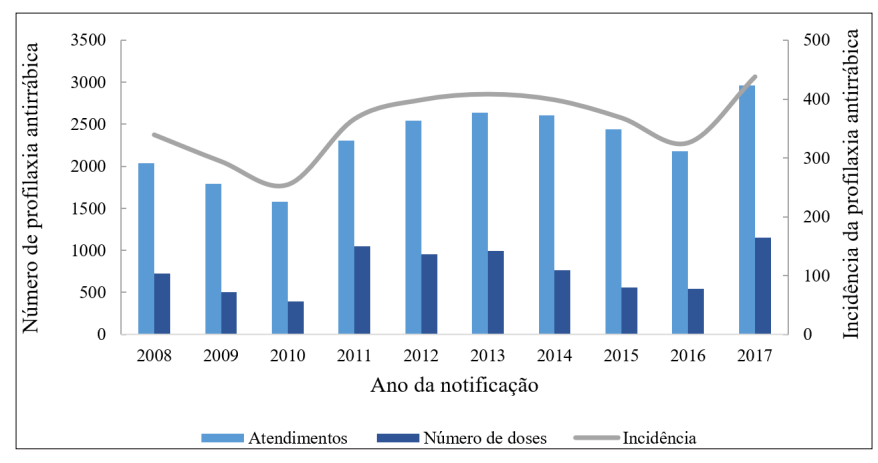

Acerca da frequência de ataques por espécie agressora (Tabela 1), são de grande relevância os casos ocasionados por caninos $81,38 \%$, gatos $11,16 \%$ e morcegos $0,71 \%$. De maneira geral, a conduta de observação associado à vacinação pós-exposição sobressai-se nos anos avaliados, com notável aumento nos últimos 4 anos. A observação do animal isoladamente aparece em segundo lugar dos métodos adotados após ataques. A opção pela vacinação isoladamente aparece na terceira posição nos últimos anos da observação. Outra importante conduta a ser destacada é a opção pelo uso de soro associado à vacinação isolada. Na avaliação apresentada, as outras opções de condutas são bastante equiparadas, dentre elas é possível citar ainda a dispensa de tratamento e o esquema de reexposição (Gráfico 2).

A expressão da frequência de ataques distribuídos pela escolaridade dos agredidos apresenta altos índices para as categorias de " 1 a a $4^{\mathrm{a}}$ série incompleta do ensino fundamental", " 5 a a $8^{\text {a }}$ série incompleta do ensino fundamental" e "ensino médio completo". É importante ressaltar a quantidade significativa de informações ignoradas e em branco nas notificações avaliadas (Gráfico 3).
A condição imediata do animal avaliada no período de 10 anos mostra grande maioria de animais sadios de forma homogênea. A categoria "Morto/Desaparecido" aparece em franco crescimento durante os anos e as categorias "Suspeito" e "Raivoso" possuem frequências muito baixas, mantendo um certo padrão (Gráfico 4).

A Tabela 2 apresenta a relação entre as espécies mais comuns envolvidas em ataques e a condição final desses animais. A grande maioria dos casos evoluiu para animais clinicamente negativos para a raiva ou negativos para exames laboratoriais para raiva. Em totalidade, 59 casos evoluíram para positivos sejam avaliações clínicas ou laboratoriais.

A apresentação da Tabela 3 contribui com a avaliação acerca dos animais que foram passíveis de observação por espécie agressora. Em sua grande maioria, os animais foram observados para acompanhamento de sua evolução clínica, em 655 casos não foi possível a observação, sendo 524 caninos e 131 felinos.

Foi observado a interrupção do tratamento antirrábico em $11,24 \%$ dos casos. Ao refinar a pesquisa, para compreender quais foram as motivações, notou-se que em 6,56\% a interrupção foi por abandono e em 4,34\% a unidade de saúde indicou a interrupção.

Quanto a frequência de indicações de uso da profilaxia antirrábica, 56,50 \% dos casos não foi necessária à sua indicação. A média de casos em que se fez uso deste recurso foi de 150,4 casos ao ano, perfazendo 6,43\%. A Figura 9, demonstra os locais anatômicos de maior frequência de ataques por animais agressores, divididos por faixa etária.

Tabela 1. Frequência de ataques subdivididos por espécie agressora. Uberlândia, Minas Gerais, Brasil, 2008 a 2017.

\begin{tabular}{lcc}
\hline Espécie de animal agressor & Frequência & $\mathbf{\%}$ \\
\hline Canina & 19.017 & $81,3 \%$ \\
Felina & 2.608 & $11,1 \%$ \\
Quiróptera (morcego) & 168 & $0,7 \%$ \\
Primata (macaco) & 68 & $0,2 \%$ \\
Raposa & 4 & $0,0 \%$ \\
Herbívoro doméstico & 64 & $0,2 \%$ \\
Outra & 1.228 & $5,2 \%$ \\
Ignorado ou em branco & 211 & $0,9 \%$ \\
Total & 23.368 & $100 \%$ \\
\hline
\end{tabular}

Gráfico 2. Conduta adotada nos casos de pós-exposição rábica subdivididos por ano de notificação. Uberlândia, Minas Gerais, Brasil, 2008 a 2017.

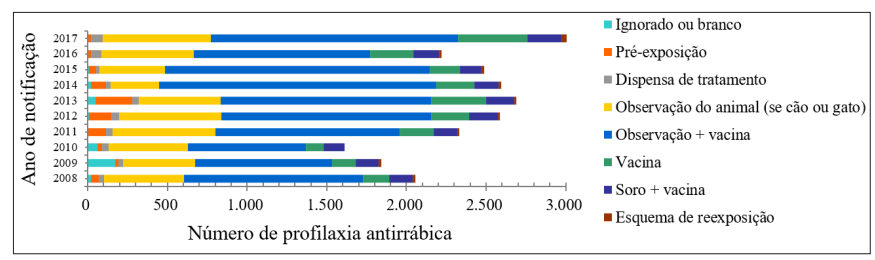


Gráfico 3. Profilaxias antirrábicas, segundo a escolaridade do indivíduo agredido em Uberlândia, Minas Gerais, Brasil, 2008 a 2017. (Ign = Ignorado, $\mathrm{EF}=$ Ensino Fundamental).

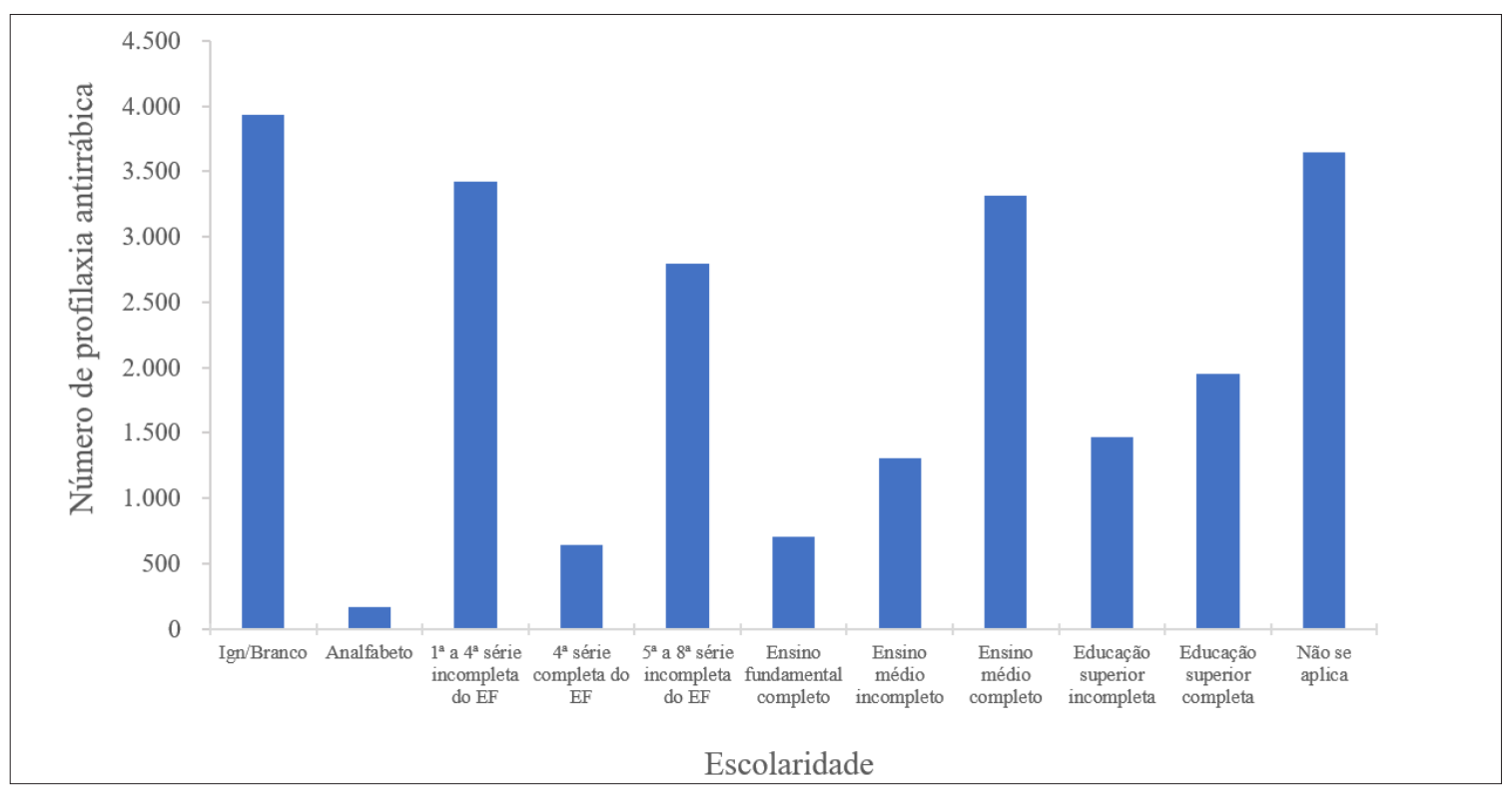

Gráfico 4. Condição do animal agressor analisado por ano de notificação. Uberlândia, Minas Gerais, Brasil, 2008 a 2017.

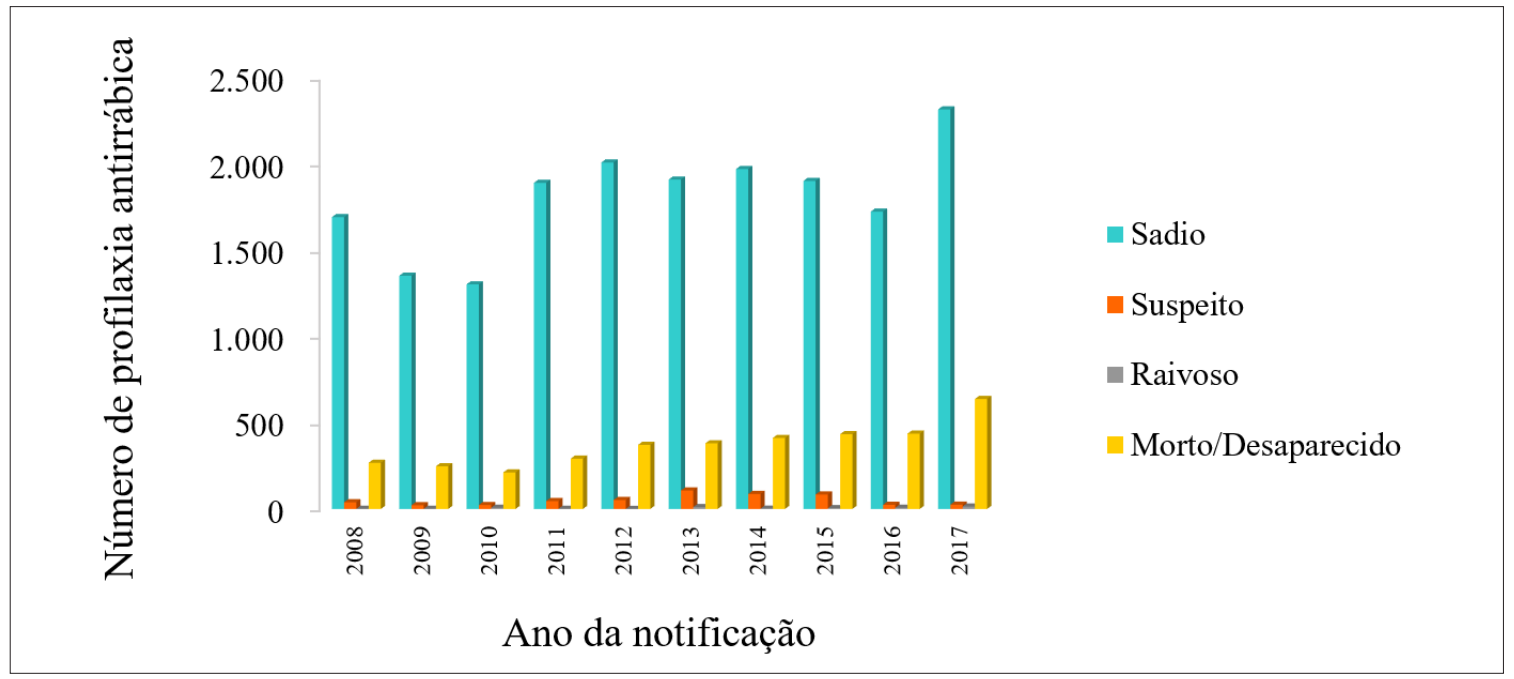

Tabela 2. Condição final do animal agressor, segundo a espécie agressora e os aspectos clínicos e laboratoriais. Uberlândia, Minas Gerais, 2008 a 2017.

\begin{tabular}{|c|c|c|c|c|c|c|c|c|c|}
\hline Condição final do animal & $\begin{array}{l}\text { Ignorado ou } \\
\text { em branco }\end{array}$ & Canina & Felina & $\begin{array}{l}\text { Quiróptera } \\
\text { (morcego) }\end{array}$ & $\begin{array}{l}\text { Primata } \\
\text { (macaco) }\end{array}$ & Raposa & $\begin{array}{l}\text { Herbívoro } \\
\text { (doméstico) }\end{array}$ & Outra & Total \\
\hline Negativo raiva clínica & 0 & 10.379 & 1.299 & 42 & 32 & 3 & 5 & 129 & 11.889 \\
\hline Negativo raiva laboratorial & 0 & 86 & 22 & 3 & 1 & 0 & 0 & 24 & 136 \\
\hline Positivo raiva clínica & 0 & 31 & 4 & 0 & 0 & 0 & 2 & 0 & 37 \\
\hline Positivo raiva laboratorial & 0 & 17 & 4 & 0 & 0 & 0 & 0 & 1 & 22 \\
\hline Ignorada ou em branco & 211 & 7.438 & 984 & 79 & 28 & 0 & 47 & 928 & 9.715 \\
\hline Total & 211 & 17.951 & 2.313 & 124 & 61 & 3 & 54 & 1.082 & 21.799 \\
\hline
\end{tabular}


Figura 1. Locais anatômicos de ataques, por animais agressores, avaliados segundo a faixa etária apresentada. Uberlândia, Minas Gerais, Brasil, 2008 a 2017.

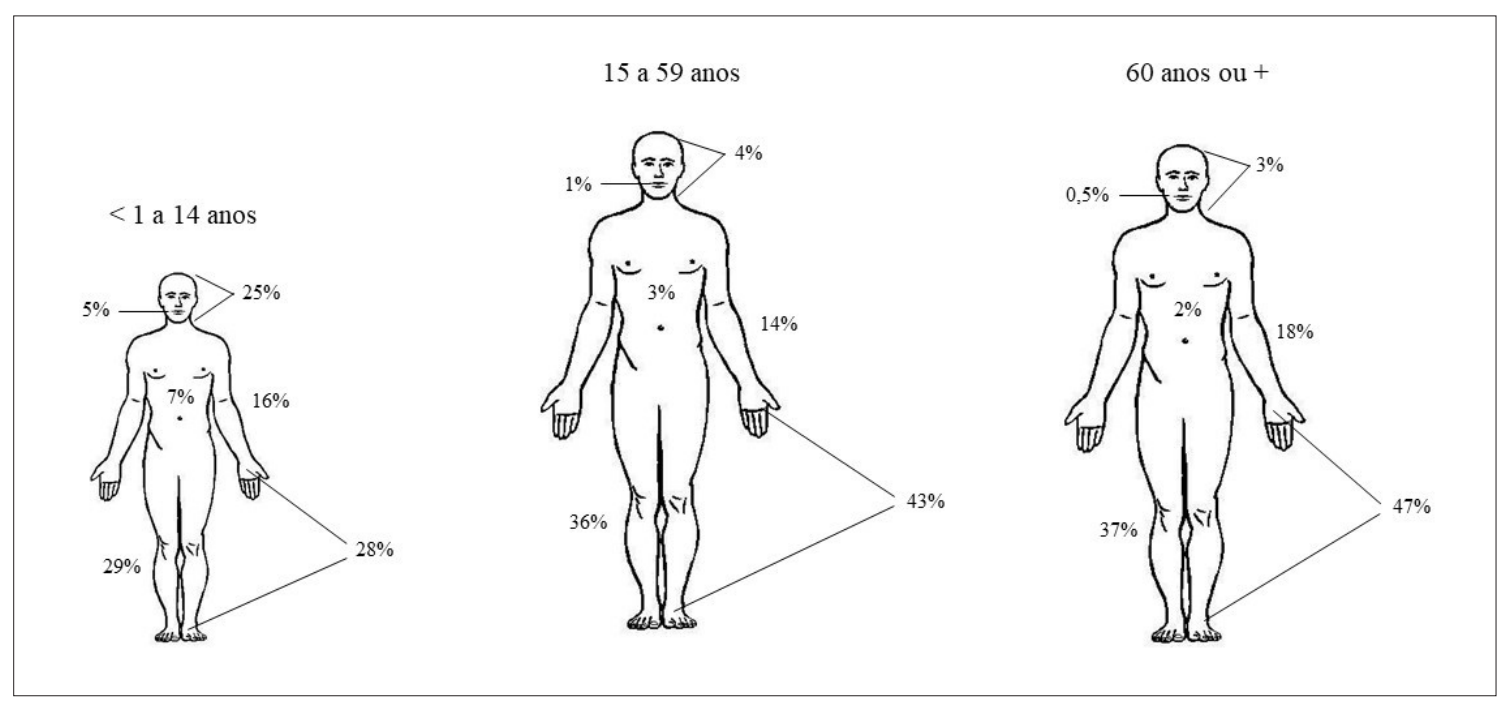

Tabela 3. Avaliação do animal agressor, passível de observação, dividido por espécie. Uberlândia, Minas Gerais, Brasil, 2008 a 2017.

\begin{tabular}{lcccc}
\hline Passível de observação & Ignorado ou em branco & Canina & Felina & Total \\
\hline Sim & 0 & 15.633 & 1.789 & 17.422 \\
Não & 0 & 524 & 131 & 655 \\
Ignorado ou em branco & 211 & 2.860 & 688 & 3.579 \\
Total & 211 & 19.017 & 2.608 & 21.656 \\
\hline
\end{tabular}

\section{DISCUSSÃO}

Os resultados obtidos demonstram expressiva frequência de ataques ao longo da série histórica analisada, confirmando a importância da avaliação continuada do perfil epidemiológico da profilaxia antirrábica. Ainda, a caracterização e o conhecimento da apresentação dos casos propiciam melhor planejamento em saúde.

A aplicação de doses pós-exposição apresenta tendência a acompanhar a característica da incidência das agressões, destaca-se o último ano de avaliação, a maior carga de aplicações segue o maior valor encontrado para incidência. As profilaxias que envolvem homens são maiores numericamente. Muito embora a diferença não tenha sido relevante.

A maioria dos casos de ataques são proporcionados por animais passíveis de domesticação e, portanto, maior convivência com os humanos. Todavia, é importante ressaltar que as campanhas de vacinação em massa dessas espécies, galga expressivo sucesso em diversos municípios do país. ${ }^{11}$ Em relação ao monitoramento animal o Centro de Controle de Zoonoses (CCZ) da Secretaria Municipal de Saúde (SMS) de Uberlândia realizou a imunização de 75.900 cães no ano de 2018. ${ }^{12}$ Com isso, cada vez mais, o envolvimento de animais silvestres e silvestres aéreos é associado a casos de raiva, principalmente quirópteros. ${ }^{5,13}$ Observações de morcegos positivos para o vírus da raiva no perímetro urbano de Uberlândia (5 morcegos positivos no ano de 2018), têm desencadeado ações de bloqueio do risco da transmissão. No ano de 2018, foram imunizados 826 cães e gatos em bloqueios realizados em episódios de encontro de morcegos positivos. ${ }^{12}$

Isso acontece pelo fato de tais espécies não serem submetidas, na maioria dos casos, à imunização ao agente rábico e ainda, difícil captura e observação de sua evolução clínica, o que necessita de medidas profiláticas diferentes daquelas exigidas quando se tem animais conhecidos pelos agredidos. ${ }^{4,714} \mathrm{Em}$ boletim epidemiológico de novembro de 2018 da cidade de Sorocaba-SP, registrou-se a captura de 7 morcegos positivos para o vírus rábico. A ocorrência gerou ação de visita domiciliar, orientação de moradores e vacinação dos animais domésticos da região em que os quirópteros foram encontrados. ${ }^{14}$

Em consonância, a conduta de observação e aplicação de vacina, adotada em grande expressão em nossa avaliação, segue o preconizado pelo MS. ${ }^{4}$ A opção pela vacinação isolada tem demonstrado expressivo crescimento e deve ser utilizada nos casos em que o acompanhamento dos agressores não for possível, o que pode cursar com a característica de aumento dos ataques por animais silvestres e silvestres aéreos. ${ }^{7}$

Os ataques rábicos são predominantes em três situações vinculados à escolaridade do agredido (Gráfico 3). Em duas 
delas, a incompletude do processo de escolarização se faz presente. Tal avaliação permite observar quais os grupos de risco para os ataques, permitindo que os órgãos de saúde responsáveis atuem preventivamente, sobretudo de forma direcionada.

Na avaliação dos ataques potencialmente rábicos, é importante a progressão da história clínica dos agressores. ${ }^{15}$ Inicialmente, a maioria destes apresenta a condição "Sadio". O aumento do número de animais mortos ou desaparecidos assim que se abre o caso, implica em maior utilização dos recursos profiláticos indicados, o que acontece principalmente no ano de 2017 (Gráfico 4). À medida que avançam as investigações diagnósticas, demonstra-se expressiva quantidade de ataques que recebem o resultado negativo para raiva clínica ou laboratorial (Tabela 2). Nota-se a importância da adoção de uma postura preventiva e, ainda, a não utilização dos recursos de profilaxia de imediato, pode-se assim optar pelo uso racional desses mecanismos. Desta maneira, a utilização consciente, onde destinam-se recursos para os casos positivados, ou em que não é possível a observação clínica de tais espécies, propicia melhor atendimento na rede de saúde.

O acompanhamento do tratamento indicado e seu seguimento são incentivados para avaliar o compromisso dos pacientes para com o projeto terapêutico proposto a eles; analisar a conduta adotada pelas unidades de saúde e ainda, a prospecção ativa dos agredidos que se ausentaram. O objetivo de avaliar a frequência de interrupção do tratamento e sua motivação se baseia em compreender se o serviço de saúde busca acompanhar os casos de maneira mais próxima e seguir o que é preconizado pelo MS. Os resultados demonstram um constante aperfeiçoamento do serviço, principalmente a partir de 2011. Entretanto, é necessário que essa informação seja valorizada durante a notificação, o que propiciaria melhor planejamento do serviço em iniciativas para diminuir o número de abandonos ou casos de tratamentos desnecessários.

No tratamento com uso de vacina antirrábica, a dose é administrada nos indivíduos que foram expostos ao vírus ou estão em risco permanente de serem expostos. A indicação de soro antirrábico pós-exposição, associada à vacinação depende principalmente, das características do animal agressor e do tipo de lesão provocada. $^{7}$ No período de 2008 a 2017 foram utilizadas baixas doses de soro antirrábico nos casos conhecidos, a grande maioria não houve indicação de seu uso. O fato pode ser explicado em associação ao alto número de casos que foram negativados clínica e laboratorialmente na apresentação da Tabela 2 sendo, portanto, uma medida acertada da rede de saúde.

\section{REFERÊNCIAS}

1. Gomes AP, Esperidião-Antonio V, Mendonça BG, Benedito HP, Vitorino RR, Prado MR, et al. Raiva humana. Rev Bras Clin Med. 2012;10(4):334-40.

2. World Health Organization. Driving progress towards rabies elimination: results of Gavi's learning agenda on rabies and new
O perfil de ataques é caracterizado, sobremaneira, pelo acometimento de extremidades corporais como pés e mãos; bem como membros inferiores e superiores. $\mathrm{O}$ fato pode ser elucidado por serem locais de compatibilidade de estatura entre as espécies agressoras (predominantemente canina) e os humanos (no caso dos membros inferiores) e por movimentos de autodefesa no momento do ataque (na situação dos membros superiores), corroborando com outros estudos dessa temática. ${ }^{16-18}$

Em todas as faixas etárias, as agressões em tronco têm baixa expressão. É provável que a razão resida no fato de ser uma área anatômica de maior proteção tanto pelo uso de vestimentas, quanto pela reação natural de exposição dos membros para afastamento do animal, áreas muito mais acometidas. As regiões de cabeça, pescoço e mucosa oral também apresentam baixos índices de notificação. O que poderia explicar os casos registrados é a possibilidade de que tenham sido provocados por animais que estivessem sendo carregados ou que os humanos possam ter aproximado tais regiões anatômicas e sofreram a agressão em resposta.

Alguns fatores foram limitantes ao andamento da avaliação como a frequência de campos registrados com informações ignoradas ou em branco em muitas variáveis analisadas. Ressaltamos que o satisfatório preenchimento desses campos possibilita uma avaliação mais condizente à realidade, propiciando atuação mais efetiva. Outro componente que deve ser melhor apresentado é o local onde ocorreram acidentes no município. Tal informação, permite o acompanhamento das áreas geográficas mais vulneráveis e que necessitam de atenção focalizada.

Quanto aos aspectos positivos encontrados neste estudo, destacamos o software livre tabulador de dados Tabwin 3.2 utilizado, que de maneira rápida e dinâmica contribuiu para a simplificação da análise dos dados. O recorte temporal de 10 anos permite uma avaliação satisfatória do perfil da raiva em Uberlândia; bem como apresenta certa padronização para futuras avaliações que devem ser realizadas rotineiramente.

Sobremaneira, a conscientização da sociedade, principalmente, daqueles submetidos a constante risco de exposição deve ser incentivada pelos órgãos de vigilância em saúde. ${ }^{1}$ Ainda, a caracterização detalhada do impacto orçamentário aos recursos disponíveis no SUS quando os atendimentos são realizados da forma preconizada pelo MS; bem como o estudo dos ataques ocorridos pelos animais silvestres e silvestres aéreos, permitirá um conhecimento mais amplo e direcionado a ações de manejo e prevenção de tais agressões.

WHO position on rabies immunization: meeting report 1-3 May 2018, Kathmandu, Nepal [Internet]. Geneva: WHO; 2019 [acesso em: 11 dezembro 2018]. Disponível: https://www.who.int/rabies/ resources/WHO-CDS-NTD-NZD-2019.01/en/

3. Grisi-Filho JH, Amaku M, Dias RA, Montenegro H Neto, Paranhos 
NT, Mendes MC, et al. Uso de sistemas de informação geográfica em campanhas de vacinação contra a raiva. Rev Saúde Pública. 2008;42(6):1005-11.

4. Ministério da Saúde. Raiva: o que é, causas, sintomas, tratamento, diagnóstico e prevenção [Internet]. Brasília: Ministério da Saúde; [acesso em: 11 dezembro 2018]. Disponível em: http://portalms. saude.gov.br/saude-de-a-z/raiva

5. Ministério da Saúde. Secretaria de Vigilância em Saúde. Departamento de Vigilância de Doenças Transmissíveis. Coordenação Geral de Doenças Transmissíveis. Casos de raiva humana por espécie animal agressora no período de 2010 a 2017. Brasília: Ministério da saúde; 2018 [acesso em: 11 dezembro 2017]. Disponível em: http://portalarquivos2.saude.gov.br/images/ pdf/2018/abril/30/Tabela-2.pdf

6. Puga LC. Modelagem espacial da ocorrência de mordeduras de morcegos hematófagos na zona da mata de minas gerais [tese]. Viçosa: Universidade Federal de Viçosa; 2015.

7. Ministério da Saúde. Nota informativa número 26/2017. Informa sobre alterações no esquema de vacinação da raiva humana pós exposição e dá outras orientações sobre alterações no esquema de vacinação da raiva humana pós-exposição e outras informações [Internet]. Brasília: Ministério da Saúde; 2017 [acesso em: 15 outubro 2018]. Disponível em: http://portalarquivos.saude.gov.br/ images/pdf/2017/agosto/04/Nota-Informativa-N-26_SEI_2017 CGPNI_DEVIT_SVS_MS.pdf

8. Ministério da Saúde. Secretaria de vigilância em saúde. Departamento de vigilância epidemiológica. Normas técnicas de profilaxia da raiva humana [Internet]. Brasília: Ministério da Saúde; 2014 [acesso em: 11 dezembro 2018]. Disponível em: https://www. saude.gov.br/images/pdf/2014/dezembro/22/Normas-tecnicasprofilaxia-raiva.pdf

9. Instituto Brasileiro de Geografia e Estatística (IBGE). Brasil/ Minas Gerais/Uberlândia [Internet]. [place unknown]: IBGE; [acesso em: 14 dezembro 2018]. Disponível em: https://cidades.ibge.gov.br/ brasil/mg/uberlandia/panorama

10. Rodrigues RF. Características do solo e estrutura fitossociológica de espécies arbóreas em dois cerradões no Triângulo Mineiro [dissertação]. Uberlândia: Universidade Federal de Uberlândia; 2009. $50 \mathrm{f}$.
11. Bocchi MR. Campanha antirrábica canina e felina: a importância da equipe de trabalho: recursos utilizados e resultados obtidos pelos municípios no desenvolvimento da campanha antirrábica canina e felina na região de São José do Rio Preto/SP, Brasil, no período de 2009 a 2013. Revista de Educação Continuada em Medicina Veterinária e Zootecnia do CRMV-SP. 2017;15(2):8-16.

12. Prefeitura de Uberlândia. Consolidado de ações realizadas em 2018 [Internet]. Boletim de Vigilância em Saúde. 2019 [acesso em: 21 jul 2019];14(14):1-14. Disponível em: http://servicos.uberlandia. mg.gov.br/uploads/cms_b_arquivos/21867.pdf

13. Ministério da Saúde. Secretaria de Vigilância em Saúde. Departamento de Vigilância de Doenças Transmissíveis. Coordenação Geral de Doenças Transmissíveis. Casos de raiva humana por espécie animal agressora no período de 1990 a 2009 [Internet]. Brasília: Ministério da Saúde; 2018 [acesso em: 22 dez 2018]. Disponível em: http://portalarquivos2.saude.gov.br/images/pdf/2018/abril/30/ Tabela-5.pdf

14. Prefeitura Municipal de Sorocaba. Secretária de Saúde. Atualização de informações epidemiológicas de arboviroses e campanha anual de vacinação antirrábica [Internet]. Boletim epidemiológico. 2018 [acesso em: $23 \mathrm{dez} 2018$ ];6(11):1-5. Disponível em: https://drive. google.com/file/d/15y7UJ2N23yIwqggKTkKJAUTqeOrc_YYj/view

15. Brasil. Ministério da Saúde. Secretaria de Vigilância em Saúde. Coordenação Geral de Desenvolvimento da Epidemiologia em Serviços. Guia de vigilância em saúde: volume único [Internet]. 2. ed. Brasília: Ministério da Saúde; 2017 [acesso em: 11 dezembro 2018]. 705 p. Disponível em: http://portalarquivos.saude.gov.br/ images/pdf/2017/outubro/06/Volume-Unico-2017.pdf

16. Lopes JT, Silva SB, Mota D, Valente SF, Vilges KM, Oliveira SV, et al. Análise dos acidentes por animais com potencial de transmissão para raiva no município de Caçapava do Sul, Estado do Rio Grande do Sul, Brasil. Rev Med Saúde Brasília. 2014;3(3):210-23.

17. Cavalcante KK, Florêncio CM, Alencar CH. Profilaxia antirrábica humana pós-exposição: características dos atendimentos no estado do Ceará, 2007-2015. J Health Biol Sci. 2017;5(4):337-45.

18. Salvi FI, Paula JM, Lutinski JA, Fritzen DM, Giachini K, Schabat FM, et al. Perfil epidemiológico dos atendimentos antirrábicas humanos no município de Chapecó, SC. Revista Interdisciplinar de Estudos em Saúde. 2018;7(1):176-86.

\section{Como citar:}

Marques AS, Silva AG Filho, Carmo DM, Afonso MP, Oliveira SV. Profilaxia antirrábica no município de Uberlândia, Minas Gerais. Rev Med UFC. 2020 abr-jun;60(2):31-37. 